\title{
Evidence-based clinical update: General anesthesia and the risk of delirium and postoperative cognitive dysfunction
}

\author{
[Mise à jour clinique fondée sur des données probantes: l'anesthésie générale et le \\ risque de délire et de dysfonctionnement cognitif postopératoire]
}

Gregory L. Bryson FRCPC MSc, Anna Wyand MD

Purpose: The purpose of this structured, evidence-based, clinical update was to identify the best evidence comparing general and regional anesthesia and their influence on delirium or cognitive dysfunction (POCD) in the postoperative period.

Source: In June 2005 a structured search of MEDLINE from 1966 to present using OVID software was undertaken. Medical subject headings and textwords describing both delirium and POCD were employed. OVID's Therapy (sensitivity) algorithm was used to maximize the detection of randomized trials. The bibliographies of eligible publications were hand-searched to identify trials not identified in the electronic search. Publications enrolling children were excluded. Levels of evidence and grades of recommendations were scored using Centre for Evidence Based Medicine criteria.

Principal findings: A total of 18 unique randomized controlled trials were identified: two evaluating delirium; ten evaluating POCD; and six evaluating both. Outcomes for delirium were abstracted from eight trials that enrolled 765 patients (387 regional anesthesia; 378 general anesthesia). Outcomes for POCD were identified from 16 trials that enrolled 2,708 patients (I,313 regional anesthesia; I,395 general anesthesia). Both delirium (II-43\%) and POCD (I5-25\%) were relatively common in trials actively seeking these outcomes. Consistent Level $2 b$ evidence suggests no significant increase in delirium in patients receiving general anesthesia compared with those receiving regional anesthesia. Similarly, consistent Level I evidence indicates that exposure to general anesthesia is not significantly associated with POCD.

Conclusion: Available randomized controlled trials suggest that there is no significant difference in the incidence of delirium or POCD when general anesthesia and regional anesthesia are compared.
Objectif : Identifier, par une mise à jour clinique structurée et fondée sur des données probantes, la meilleure preuve en comparant l'anesthésie générale et régionale et leur influence sur le délire ou le dysfonctionnement cognitif postopératoires (DCPO).

Source : En juin 2005, une recherche structurée a été entreprise dans MEDLINE, de 1966 à nos jours, en utilisant le logiciel OVID. Les vedettes-matières et les textes décrivant le délire et le DCPO ont été utilisés. Un algorithme thérapeutique (sensibilité) tiré de OVID a servi à optimaliser la détection d'études randomisées. Les bibliographies des études admissibles ont été fouillées manuellement pour découvrir les études non repérées dans la recherche électronique. Les recherches portant sur des enfants ont été exclues. Les niveaux d'évidence et les degrés de recommandations ont été évalués selon les critères du Centre for Evidence Based Medicine.

Constatations principales: Nous avons trouvé 18 études randomisées et contrôlées originales : deux évaluaient le délire, dix le $D C P O$ et six évaluaient les deux. Les données sur le délire ont été extraites de huit études regroupant 765 patients (387 pour l'anesthésie régionale et 378 pour l'anesthésie générale). Les données sur le DCPO ont été tirées de 16 études sur 2708 patients (I 3/3 pour l'anesthésie régionale et I 395 pour l'anesthésie générale). Le délire (II - $43 \%)$ et le DCPO ( $15-25 \%)$ étaient relativement fréquents dans les études qui recherchaient activement ces résultats. L'évidence d'un niveau $2 b$ persistant montre qu'il n'y a pas d'augmentation significative du délire chez les patients sous anesthésie générale comparée à l'anesthésie régionale. De même, l'évidence d'un niveau I persistant indique que l'exposition à l'anesthésie générale n'est pas significativement associée au DCPO.

Conclusion: Les études randomisées et contrôlées accessibles montrent que l'incidence de délire ou de DCPO n'est pas significativement différente avec l'anesthésie générale ou régionale.

From the Department of Anesthesiology, The Ottawa Hospital, University of Ottawa, Ottawa, Ontario, Canada.

Address correspondence to: Dr. Gregory L. Bryson, Department of Anesthesiology, Box 249C, The Ottawa Hospital - Civic Campus, 1053 Carling Avenue, Ottawa, Ontario KlY 4E9, Canada. Phone: 613-761-4169; Fax: 613-761-5209; E-mail: glbryson@ottawahospital.on.ca Disclosure: This work was supported by the Departments of Anesthesiology at The Ottawa Hospital and the University of Ottawa. The authors declare no commercial or non-commercial affiliations that are or may be perceived to be a conflict of interest with the work, and any other associations such as consultancies.

Accepted for publication February 10, 2006.

Revision accepted February 21, 2006. 


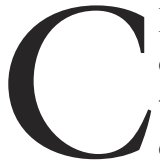

HANGES in cognitive function frequently complicate the postoperative course of the elderly patient undergoing non-cardiac surgery. Many patients and physicians implicate general anesthesia in the etiology of adverse cognitive outcomes: published research challenges this assumption. This clinical controversy will be addressed using the "Evidence-Based Clinical Update" structure of the Canadian Journal of Anesthesia.

\section{Clinical question}

During your preoperative assessment a 74-yr-old patient informs you that her last operation, a sigmoid colon resection for cancer, was complicated by postoperative confusion. On the evening of the first postoperative day she experienced visual hallucinations and was disoriented to place and time. She states that "she's not been the same" since her surgery. She is more forgetful and has difficulty concentrating. In preparation for her total hip arthroplasty she would prefer a general anesthetic and wants assurance that your anesthetic will not cause further changes in her thinking.

As her upcoming surgery is amenable to either regional or general anesthesia you ask yourself "Does general anesthesia increase the risk of delirium or cognitive dysfunction in the postoperative period?" Seeking an evidence-based answer to this clinical problem you turn to the literature.

\section{Methods}

In June 2005 a structured search of MEDLINE from 1966 to present using OVID software was undertaken with the assistance of a reference librarian. Medical subject headings and textwords describing both delirium and postoperative cognitive dysfunction (POCD) were employed (Appendix 1). OVID's Therapy (sensitivity) algorithm was used to maximize the detection of randomized trials while excluding non-randomized research (Appendix 2). One hundred eligible studies were identified using the delirium search strategy: 89 were identified for POCD.

Trials included in this review met the following criteria: enrolled adult patients undergoing non-cardiac surgery; randomly assigned patients to either regional or general anesthesia; and reported at least one measurement of cognitive outcome. Two investigators (GLB and AW) independently reviewed the abstracts of the trials to identify eligible research. The bibliographies of eligible publications were hand-searched to identify trials not identified in the electronic search.

Reviewers abstracted each trial using a standardized Excel spreadsheet (Microsoft Excel 2002, Mississauga, ON, Canada). Details from each study abstracted included: type of surgery, design of trial, anesthetics compared, outcome (delirium or POCD), outcome measure used; timing of outcome measurement; outcome definition; numbers of patients with postoperative cognitive impairment in regional and general anesthesia groups, primary finding of the study. Trials assessing delirium were those describing delirium, confusion, or using standardized measures of delirium. Trials assessing POCD were those using specific measures of cognitive function. Trials assessing both delirium and POCD were included in both reviews.

The likelihood of methodological bias was assessed using the Jadad score (Appendix 3). ${ }^{1}$ The Jadad score assigns points for three key items of trial design: randomization, blinding, and accounting for withdrawals. The maximum possible score is $\mathbf{5}$. Trials scoring 3 or more are generally considered to be of good methodological quality.

Following abstraction of all methodological information both reviewers assigned a Level of Evidence for each trial using the Centre for Evidence Based Medicine guidelines for Therapy. ${ }^{2}$ This review preferentially cites evidence of the highest quality available and rejects case reports and case control studies when randomized trials were available. Centre for Evidence Based Medicine Levels of Evidence and Grades of Recommendation are described in Appendices 4a and 4b.

\section{Review of current best evidence}

Review of abstracts revealed ten eligible trials assessing either delirium or POCD..$^{3-12}$ Hand search identified an additional 17 articles $^{13-29}$ so that a total of 27 articles were reviewed in detail. Seven publications were excluded for using a non-randomized ${ }^{18,19,24,27,29}$ or pseudo-randomized designs. ${ }^{23,26}$ A single trial, published in Japanese, was excluded when a translator could not be identified. ${ }^{7}$ A single systematic review was identified and will be discussed separately. ${ }^{12}$ Following review of outcome definitions and measures a total of 18 unique randomized controlled trials were identified: two evaluating delirium; ten evaluating POCD; and six evaluating both. Outcomes for delirium were abstracted from eight trials that enrolled 765 patients (387 regional; 378 general). Outcomes for POCD were identified from 16 trials that enrolled 2,708 patients (1,313 regional; 1,395 general). Key features of included trials are summarized in Tables I and II.

\section{Delirium}

Delirium is a transient, fluctuating disturbance of consciousness, attention, cognition, and perception ${ }^{30}$ that complicates the course of $36.8 \%$ (range $0-73.5 \%$ ) of surgical patients. ${ }^{31}$ Delirium is a harbinger of poor 
TABLE I Trials evaluating postoperative delirium

\begin{tabular}{|c|c|c|c|c|c|}
\hline Study & Comparators & $n$ & Jadad & Outcome & $C E B M$ \\
\hline Berggren, 1987 & GA, EA & 57 & 1 & $\begin{array}{l}11 / 29 \text { GA vs } 14 / 28 \text { EA "confused" as assessed by the organic } \\
\text { brain syndrome acale, } P>0.05\end{array}$ & $2 \mathrm{~b}$ \\
\hline Bigler, 1985 & GA, SA & 40 & 1 & $1 / 20$ GA ps $1 / 20$ SA "confused," $P>0.05$ & $2 b$ \\
\hline Campbell, 1993 & GA, RBB & 157 & 2 & $\begin{array}{l}\text { No group/time interaction on Felix Post Unit Questionnaire, } \\
P>0.05\end{array}$ & $2 b$ \\
\hline Chung, 1987 & GA, SA & 44 & 1 & $3 / 24$ GA ps $0 / 24$ SA “confused," $P>0.05$ & $2 \mathrm{~b}$ \\
\hline Chung, 1989 & GA, SA & 44 & 1 & $2 / 22$ GA vs $0 / 22$ SA “confused," $P>0.05$ & $2 \mathrm{~b}$ \\
\hline Cook, 1986 & GA, SA & 101 & 2 & 6/51 GA vs $9 / 51$ SA “confused," $P>0.05$ & $2 \mathrm{~b}$ \\
\hline Crul, 1992 & GA, SA & 60 & 1 & $\begin{array}{l}\text { Scores on Hospital Observation List were less favourable in } \\
\text { SA patients on POD }, P<0.05\end{array}$ & $2 \mathrm{~b}$ \\
\hline Williams-Russo, 1995 & GA, EA & 262 & 3 & $12 / 128$ GA ps $16 / 134$ EA delirious by DSMIII criteria, $P=0.50$ & $\mathrm{lb}$ \\
\hline
\end{tabular}

TABLE II Characteristics of trials evaluating postoperative cognitive dysfunction

\begin{tabular}{|c|c|c|c|c|c|}
\hline Study & Comparators & $n$ & Jadad & Outcome & $C E B M$ \\
\hline Asbjorn, 1989 & GA, EA & 40 & 1 & $\begin{array}{l}\text { No group/time interaction on pooled } \mathrm{z} \text { scores of five tests } \\
\text { of cognition, } P>0.05\end{array}$ & $2 b$ \\
\hline Bigler, 1985 & GA, SA & 40 & 1 & No group/time interaction on Abbreviated Mental Test, $P>0.05$ & $2 b$ \\
\hline Campbell, 1993 & GA, RBB & 157 & 2 & $\begin{array}{l}\text { No group/time interaction on eight individual tests } \\
\text { of cognition, } P>0.05\end{array}$ & $2 b$ \\
\hline Chung, 1987 & GA, SA & 44 & 1 & $\begin{array}{l}\text { Score on Mini-Mental State less favourable in GA group six hours } \\
\text { postoperatively, } P<0.001 \text {. Otherwise no difference to POD } 5\end{array}$ & $2 b$ \\
\hline Chung, 1989 & GA, SA & 44 & 1 & $\begin{array}{l}\text { No group/time interaction on two individual tests } \\
\text { of cognition, } P>0.05\end{array}$ & $2 b$ \\
\hline Crul, 1992 & GA, SA & 101 & 1 & $\begin{array}{l}\text { No group/time interaction on three individual tests } \\
\text { of cognition, } P>0.05\end{array}$ & $2 b$ \\
\hline Forster, 1990 & GA, EA, SA & 64 & 2 & No group/time interaction on Mini-Mental State, $P>0.05$ & $2 b$ \\
\hline Fredman, 1998 & GA, SA & 100 & 1 & $\begin{array}{l}\text { Score on Digit Symbol Substitution Test less favourable in GA } \\
\text { group } 15 \text { min postoperatively, } P<0.05 \text {. Otherwise no difference to } \\
\text { two hours postoperatively }\end{array}$ & $2 b$ \\
\hline Ghoneim, 1988 & GA, SA & 91 & 3 & $\begin{array}{l}\text { No group/time interaction on } 17 \text { individual tests } \\
\text { of cognition, } P>0.05\end{array}$ & $1 b$ \\
\hline Hole, 1980 & GA, EA & 60 & 2 & $\begin{array}{l}8 / 31 \text { GA vs } 1 / 29 \text { EA noted by investigators to have } \\
\text { "mental changes" in hospital, } P<0.01 \\
12 / 31 \text { GA vs } 8 / 29 \text { EA self-reported "mental changes" } \\
\text { following discharge, } P>0.05\end{array}$ & $2 b$ \\
\hline Jones, 1990 & GA, SA & 146 & & $\begin{array}{l}\text { Score on Choice Reaction Time less favourable in SA group } \\
90 \text { days postoperatively, } P=0.04 \text {. Otherwise, no group/time } \\
\text { interaction on five individual tests of cognition, } P>0.05\end{array}$ & $2 b$ \\
\hline Nielson, 1990 & GA, SA & 64 & 2 & $\begin{array}{l}\text { Scores on } 31 \text { individual tests of cognition grouped into } 12 \text { discrete } \\
\text { cognitive abilities. No group/time interaction noted, } P>0.05\end{array}$ & $2 b$ \\
\hline Rasmussen, 2003 & GA, EA, SA & 428 & 3 & $\begin{array}{l}\text { Scores on seven individual tests of cognition adjusted to control for } \\
\text { "learning effect" and converted to } \mathrm{z} \text { scores. POCD defined as } \\
\mathrm{Z}>1.96 \text { on two individual tests or on sum of all seven tests. } \\
37 / 188 \text { GA vs } 22 / 176 \text { RA had POCD on POD7, } P=0.06 \\
25 / 175 \text { GA vs } 23 / 165 \text { RA had POCD on POD90, } P=0.93\end{array}$ & $\mathrm{lb}$ \\
\hline Riis, 1983 & GA, EA, & 30 & 1 & $\begin{array}{l}\text { Scores on } 13 \text { individual tests of cognition grouped into four } \\
\text { discrete cognitive abilities and converted to } \mathrm{z} \text { scores. No group/time } \\
\text { interaction noted, } P>0.05\end{array}$ & $2 b$ \\
\hline Somprakit, 2002 & GA, EA, SA & 60 & 2 & $\begin{array}{l}\text { No group/time interaction on Thai Mini-Mental State } \\
\text { Examination, } P>0.05\end{array}$ & $2 b$ \\
\hline Williams-Russo, 1995 & GA, EA & 262 & 3 & $\begin{array}{l}\text { No group effect noted on ten individual tests of cognition, } \\
P>0.005 \text { corrected for multiple } t \text { tests. } \\
\text { MCID of ten individual tests of cognition were defined. If test result: } \\
\text { less favourable than MCID }=-1 \text {; within MCID }=0 \text {; more favourable } \\
\text { than }=+1 \text {. Plus } / \text { minus scores on ten tests added. If }-4 \text { or less POCD } \\
\text { was diagnosed. Using this definition } 5 / 177 \text { GA vs } 7 / 114 \text { EA had } \\
\text { POCD on POD180, } P=0.50 \text {. }\end{array}$ & $1 b$ \\
\hline
\end{tabular}

GA = general anesthesia; $\mathrm{SA}=$ spinal anesthesia; $\mathrm{EA}=$ epidural anesthesia; $\mathrm{RBB}=$ retrobulbar block; $\mathrm{RA}=$ pooled $\mathrm{EA}$ and $\mathrm{SA} ; \mathrm{Jadad}=$ Jadad Score (maximum score $=5$ ); CEBM $=$ Centre for Evidence Based Medicine Level of Evidence (la best evidence -5 expert opinion); $\mathrm{POD}=$ postoperative day; $\mathrm{POCD}=$ postoperative cognitive dysfunction; $\mathrm{MCID}=$ minimally clinically important differences. 
patient outcome and is associated with increased length of hospital stay, ${ }^{32}$ greater rates of nursing home placement, ${ }^{33}$ and mortality rates approaching 30\%. ${ }^{34}$ Despite the clinical importance of delirium in the perioperative period there has been surprisingly little research on the influence of anesthetic technique on its occurrence.

In seven of the eight trials identified, enrolling a total of 705 patients, the choice of general or regional anesthesia bore no influence on the occurrence of delirium. Only a single trial ${ }^{17}$ of 60 patients identified a statistically significant difference in the incidence of delirium/confusion associated with the use of regional anesthesia. In this trial, patients assigned to regional anesthesia experienced less favorable scores of cognitive function on the first postoperative day but were otherwise similar to those assigned to general anesthesia.

Research regarding the influence of anesthetic technique on the incidence of delirium has been further limited by weak research methodology. Of the eight trials reviewed two employed validated tools for the detection and diagnosis of delirium, ${ }^{3,11}$ two relied on institution-specific questionnaires that had not been validated, ${ }^{4,17}$ and the remainder relied on reports of patient behaviour from health care workers and family. In the absence of a formal screening tool both physicians and nurses fail to diagnose delirium in over twothirds of cases. Indeed, the incidence of delirium was greater in those trials using properly validated assessment tools (11-43\%) than in those trials using bedside reports $(5-15 \%)$. Failure to properly assess and define delirium as an outcome suggests that research in this field is underreporting and/or incorrectly classifying this important event. Furthermore, only a single triall ${ }^{11}$ scored 3 or more on the Jadad score of methodological bias. It is difficult or impossible to blind both patients and anesthesiologists to the allocation of regional or general anesthesia thus limiting the maximum scores possible. That said, few trials reported randomization methods or patient withdrawals, both factors associated with a reduction in bias.

Within the methodological limitations discussed above the clinician wishing to answer the question "Does general anesthesia increase the risk of delirium in the postoperative period?" can rely on consistent Level $2 \mathrm{~b}$ evidence from randomized trials to inform their decision. No significant increase in the incidence of delirium associated with general anesthesia was found in the available trials. It is not possible to rule out the possibility of an effect given the relatively small sample size of the available trials and inconsistent surveillance for delirium. More study is required.

\section{Postoperative cognitive dysfunction}

Postoperative cognitive dysfunction is a subtle disorder of thought processes that may influence isolated domains of cognition such as verbal memory, visual memory, language comprehension, visuospatial abstraction, attention, or concentration. Postoperative cognitive dysfunction following cardiopulmonary bypass is well described and has now been documented in $25.8 \%$ (95\% confidence interval 23.1-28.5) of patients one week after non-cardiac surgery. ${ }^{35}$ Patients demonstrating POCD one week after surgery experience a decline in their activities of daily living ${ }^{35}$ and quality of life ${ }^{36}$ following hospital discharge and are nearly three times as likely to suffer cognitive decline one to two years postoperatively (odd ratio $2.84 ; 95 \%$ confidence interval 1.35-5.96). ${ }^{37}$

If research on postoperative delirium can be faulted for not using validated assessment tools then research on POCD can perhaps be accused of using too many assessment tools. Studies identified in this review used anywhere between one and 31 individual tests of $\operatorname{cog}$ nition. Most of these tests are subsets of test banks used for the assessment of memory and intelligence in adults. Few of the tests employed define a score at which a given patient can be said to be impaired. For this reason only three trials ${ }^{9,11,22}$ quoted rates of POCD ranging from 15-25\% in-hospital and 5-10\% following discharge. Instead, most trials report mean scores for each individual test at varying times, then assess differences between points-in-time and between groups using analysis of variance.

Only a single trial ${ }^{22}$ of 60 patients identified a statistically significant decline in cognitive outcome associated with general anesthesia. This trial used no test of cognitive function but instead relied on a bedside clinical assessment of the patient's "mental status" by the investigators and family members. When patients were assessed following discharge from hospital there was no difference in cognitive outcome between regional and general anesthesia. The remaining 15 trials detected a decrease in cognitive scores in the immediate postoperative period followed by steady improvement in scores that often exceed baseline assessment by hospital discharge. This change in scores over time is referred to, in statistical terms, as a within-group effect. It should be noted that the improvement in scores seen might reflect the characteristics of the test used rather than an improvement in the patient's cognitive abilities per se. Few cognitive tests are designed for repeated testing and many patients score better on them with practice, a so-called learning effect. Despite the significant within-group effect noted, the choice of anesthetic technique was associated neither with a significant dif- 
ference in scores overall (a between-groups effect) nor with a significant difference in scores at any given time point (group-time interaction). When the math is said and done it is apparent that there is no statistically significant difference in cognitive outcome associated with the choice between regional and general anesthesia.

Similar to the findings in delirium research, trials assessing POCD suffered from a lack of blinding and scored relatively poorly on the Jadad score. Only three of the 16 trials reviewed scored 3 or greater ${ }^{9,11,20}$ but these three trials provide consistent Level $\mathrm{lb}$ evidence suggesting that the choice of regional or general anesthesia bears no impact on the occurrence of POCD.

Unlike delirium research, POCD has been the subject of a systematic review. ${ }^{12}$ Conducted in 2003, this systematic review identified 19 randomized controlled trials and four observational studies. Only one of 19 randomized trials ${ }^{22}$ and none of the observational trials in this systematic review reported a statistically significant difference in cognitive outcomes with regional anesthesia. In comparison, this evidencebased clinical update limited itself to randomized controlled trials, excluded four trials using non- or pseudo-random allocation methods, and included one French-language publication. The variety of outcome measures employed precluded statistical pooling of the results (meta-analysis) but the qualitative results of this systematic review are consistent (homogenous) and can be graded as Level la evidence.

After reviewing the statistics and available data, the clinician wishing to answer the question "Does general anesthesia increase the risk of POCD in the postoperative period?" can rely on consistent Level 1 evidence from a systematic review and three randomized controlled trials, as well as Level $2 \mathrm{~b}$ evidence from 13 other randomized trials, to inform their decision. Best available evidence indicates that the choice between regional and general anesthesia bears no statistically significant influence on the likelihood of postoperative POCD.

\section{Conclusions}

Delirium and POCD are common complications among patients undergoing anesthesia and surgery. Prevention and treatment of postoperative cognitive outcomes are challenges for the anesthesiologist interested in perioperative medicine. Review of the best available evidence, from systematic review and randomized controlled trials, suggests that general anesthesia is not associated with a statistically significant influence on the occurrence of cognitive change following surgery. What other factors might play a role in postoperative cognitive outcomes?
Increasing age predicts both delirium ${ }^{38}$ and POCD $^{35}$ suggesting that older patients may have preexisting conditions or limited reserve to cope with the physiological challenges of anesthesia and surgery. A relationship between physiological stress and cognitive change is suggested by studies that frequently identify delirium and POCD following major/complicated surgery ${ }^{35,38}$ but note it rarely following minor ambulatory surgery. ${ }^{39}$ Unfortunately none of these characteristics can be modified by the anesthesiologist. Could selection of drugs used in the perioperative period play a role?

While the pathophysiology of delirium is incompletely understood it likely involves relative decreases in muscarinic cholinergic activity, increases in dopaminergic activity, or some combination of both. ${ }^{40} \mathrm{~A}$ cholinergic model is supported by observational research in hospitalized elders that demonstrates a nearly twofold increase in the risk of delirium in patients exposed to diphenhydramine, a drug with well known anticholinergic properties. ${ }^{41}$ Less still is known about the pathophysiology of POCD; however, failure of cholinergic neurotransmission is also felt to be central to the mechanism of other cognitive disorders such as Alzheimer's disease and vascular dementia. ${ }^{42}$ Pharmacologic management strategies based on central cholinergic and dopaminergic neurotransmission await future prospective trials.

Review of the existing literature on anesthesia and cognitive outcomes suggests that investigators conducting these future trials must improve their methods. Simple, validated tools for the assessment of delirium are available for use in both ward ${ }^{43}$ and intensive care ${ }^{44}$ settings. The work of the International Study of Perioperative Cognitive Dysfunction ${ }^{45}$ and consensus recommendations for the assessment of cognition following cardiac surgery ${ }^{46,47}$ should be reviewed by investigators interested in POCD. Going forward, investigators should develop a standardized suite of assessment tools, analysis methods that correct for multiple comparisons and learning effect, and an agreed-upon definition of POCD.

\section{Recommendations}

Returning to our patient you can offer her only limited reassurance. The patient can be told that she is not unique in her experience, as both delirium and POCD are relatively common occurrences following anesthesia and surgery. You can provide a Grade B recommendation based on consistent Level $2 \mathrm{~b}$ evidence that the choice between general anesthesia and regional anesthesia for her procedure has not been associated with an increased risk of developing post- 
operative delirium. Furthermore, you can provide a Grade A recommendation based on consistent Level $\mathrm{la}$ and $\mathrm{lb}$ evidence that her choice will not influence her likelihood of developing further lasting changes in her memory and concentration. Unfortunately, a more satisfying answer, with evidence-based prophylaxis and treatment options for postoperative cognitive outcomes, awaits further research.

\section{APPENDIX 1 Literature search}

Database: OVID MEDLINE(R) <1966 to June Week 4 2005>

Search strategy:

1. exp ANESTHESIA/ (109722)

2. exp Cognition Disorders/ (25276)

3. postoperative cognitive dysfunction.mp. (55)

4. 2 or $3(25282)$

5. 1 and 4 (128)

6. limit 5 to "therapy (sensitivity)" (89)

7. from 6 keep 1-89 (89)

Database: OVID MEDLINE(R) <1966 to June Week 4 2005>

Search strategy:

1. exp ANESTHESIA/ (109722)

2. exp DELIRIUM/ or delirium.mp. (13488)

3. delirious.mp. (534)

4. 2 or $3(13663)$

5. $\quad 1$ and 4 (123)

6. limit 5 to "therapy (sensitivity)" (100)

7. from 6 keep 1-100 (100)

\section{APPENDIX 2 OVID Limit "Therapy} (Sensitivity)"

1. randomized controlled trial.pt.

2. dt.fs. [dt=drug therapy]

3. tu.fs. [tu=therapeutic use]

4. random $\$ . t w$.

5. or $/ 1-4$

\section{APPENDIX 3 Jadad score}

Please read the article and try to answer the following questions:

1. Was the study described as randomized (this includes the use of words such as randomly, random, and randomization)?

2. Was the study described as double blind?

3. Was there a description of withdrawals and dropouts?

Scoring the items:

Either give a score of 1 point for each "yes" or 0 points for each "no." There are no in-between marks.

Give 1 additional point

If for question $\mathrm{l}$, the method to generate the sequence of randomization was described and it was appropriate (table of random numbers, computer generated, etc.)

and/or:

If for question 2, the method of double blinding was described and it was appropriate (identical placebo, active placebo, dummy, etc.)

Deduct 1 point if:

If for question 1 , the method to generate the sequence of randomization was described and it was inappropriate (patients were allocated alternately, or according to date of birth, hospital number, etc.)

and/or:

For question 2, the study was described as double blind but the method of blinding was inappropriate (e.g., comparison of tablet $v$ s injection with no double dummy)

Jadad AR, Moore RA, Carroll D, et al. Assessing the quality of reports of randomized clinical trials: is blinding necessary? Control Clinical Trials 1996; 17: 1-12. 


\section{APPENDIX 4a Levels of evidence for studies about therapy or harm}

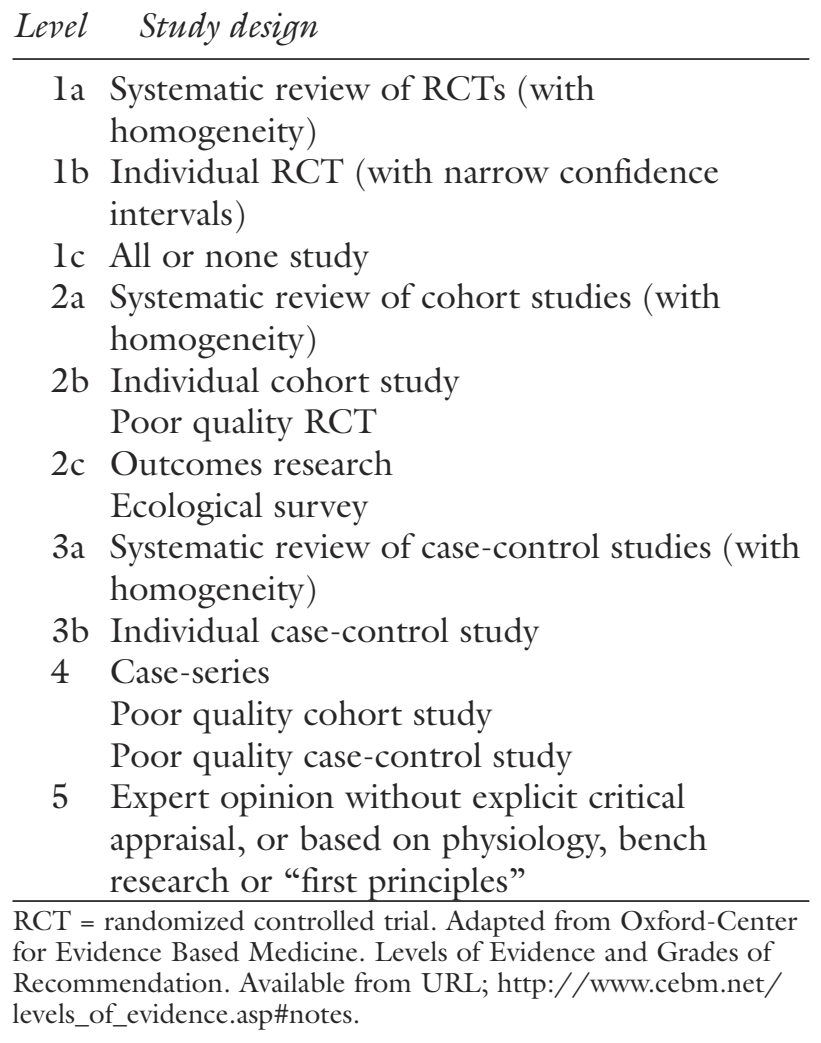

\section{APPENDIX 4b Grades of recommendation}

Grade Level of evidence

A Consistent Level 1 studies

B Consistent Level 2 or 3 studies Extrapolations from Level 1 studies

C Level 4 studies Extrapolations from Level 2 or 3 studies

D Level 5 evidence Troublingly inconsistent or inconclusive studies of any level

Extrapolations - data used in a situation with clinically important differences from original study population. Adapted from OxfordCenter for Evidence Based Medicine. Levels of Evidence and Grades of Recommendation. Available from URL; http://www. cebm.net/levels_of_evidence.asp\#notes.

\section{References}

1 Jadad AR, Moore RA, Carroll D, et al. Assessing the quality of reports of randomized clinical trials: is blinding necessary? Control Clin Trials 1996; 17: 1-12.

2 Phillips B, Ball C, Sackett D, et al. Levels of evidence and grades of recommendation. Available from URL; http://www.cebm.net/levels_of_evidence.asp, 2003.

3 Berggren D, Gustafson Y, Eriksson B, et al. Postoperative confusion after anesthesia in elderly patients with femo- ral neck fractures. Anesth Analg 1987; 66: 497-504.

4 Campbell DN, Lim M, Muir MK, et al. A prospective randomised study of local versus general anaesthesia for cataract surgery. Anaesthesia 1993; 48: 422-8.

5 Chung F, Meier R, Lautenschlager E, Carmichael FJ, Chung A. General or spinal anesthesia: which is better in the elderly? Anesthesiology 1987; 67: 422-7.

6 Forster A, Altenburger H, Gamulin Z. Effects of anesthesia on higher brain functions in the elderly (French). Presse Med 1990; 19: 1577-81.

7 Kamitani K, Higuchi A, Asabi T, Yoshida $H$. Postoperative delirium after general anesthesia vs. spinal anesthesia in geriatric patients (Japanese). Masui 2003; 52: 972-5.

8 Nielson WR, Gelb AW, Casey JE, Penny FJ, Merchant $R N$, Manninen PH. Long-term cognitive and social sequelae of general versus regional anesthesia during arthroplasty in the elderly. Anesthesiology 1990; 73: 1103-9.

9 Rasmussen LS, Johnson T, Kuipers HM, et al. Does anaesthesia cause postoperative cognitive dysfunction? A randomised study of regional versus general anaesthesia in 438 elderly patients [see comment]. Acta Anaesthesiol Scand 2003; 47: 260-6.

10 Somprakit P, Lertakyamanee J, Sattararatanamai C, et al. Mental state change after general and regional anesthesia in adults and elderly patients, a randomized clinical trial. J Med Assoc Thai 2002; 85(Suppl 3): S875-83.

11 Williams-Russo P, Sharrock NE, Mattis S, Szatrowski TP, Charlson ME. Cognitive effects after epidural vs general anesthesia in older adults. A randomized trial. JAMA 1995; 274: 44-50.

12 Wu CL, Hsu W, Richman JM, Raja SN. Postoperative cognitive function as an outcome of regional anesthesia and analgesia. Reg Anesth Pain Med 2004; 29: 25768.

13 Asbjorn J, Jakobsen BW, Pilegaard HK, Blom L, Ostergaard A, Brandt MR. Mental function in elderly men after surgery during epidural analgesia. Acta Anaesthesiol Scand 1989; 33: 369-73.

14 Bigler D, Adelhoj B, Petring OU, Pederson NO, Busch $P$, Kalbke $P$. Mental function and morbidity after acute hip surgery during spinal and general anaesthesia. Anaesthesia 1985; 40: 672-6.

15 Chung FF, Chung A, Meier RH, Lautenschlaeger E, Seyone $C$. Comparison of perioperative mental function after general anaesthesia and spinal anaesthesia with intravenous sedation. Can J Anaesth 1989; 36: 382-7.

16 Cook PT, Davies MJ, Cronin KD, Moran P. A prospective randomised trial comparing spinal anaesthesia using hyperbaric cinchocaine with general anaesthesia for lower limb vascular surgery. Anaesth Intensive Care 
1986; 14: 373-80.

17 Crul BJ, Hulstijn W, Burger IC. Influence of the type of anaesthesia on post-operative subjective physical well-being and mental function in elderly patients. Acta Anaesthesiol Scand 1992; 36: 615-20.

18 Edwards H, Rose EA, Schorow M, King TC. Postoperative deterioration in psychomotor function. JAMA 1981; 245: 1342-3.

19 Fredman B, Zohar E, Philipov A, Olsfanger D, Shalev $M$, Jedeikin $R$. The induction, maintenance, and recovery characteristics of spinal versus general anesthesia in elderly patients. J Clin Anesth 1998; 10: 623-30.

20 Ghoneim MM, Hinrichs JV, O'Hara MW, et al. Comparison of psychologic and cognitive functions after general or regional anesthesia. Anesthesiology 1988; 69: 507-15.

21 Haan J, van Kleef JW, Bloem BR, et al. Cognitive function after spinal or general anesthesia for transurethral prostatectomy in elderly men. J Am Geriatr Soc 1991; 39: 596-600.

22 Hole A, Terjesen T, Breivik $H$. Epidural versus general anaesthesia for total hip arthroplasty in elderly patients. Acta Anaesthesiol Scand 1980; 24: 279-87.

23 Hughes D, Bowes JB, Brown MW. Changes in memory following general or spinal anaesthesia for hip arthroplasty. Anaesthesia 1988; 43: 114-7.

24 Jhaveri $R M$. The effects of hypocapnic ventilation on mental function in elderly patients undergoing cataract surgery. Anaesthesia 1989; 44: 635-40.

25 Jones MJ, Piggott SE, Vaughan RS, et al. Cognitive and functional competence after anaesthesia in patients aged over 60: controlled trial of general and regional anaesthesia for elective hip or knee replacement. BMJ 1990; 300: 1683-7.

26 Karhunen U, Jonn G. A comparison of memory function following local and general anaesthesia for extraction of senile cataract. Acta Anaesthesiol Scand 1982; 26: 291-6.

27 O'Hara DA, Duff A, Berlin JA, et al. The effect of anesthetic technique on postoperative outcomes in hip fracture repair. Anesthesiology 2000; 92: 947-57.

28 Riis J, Lombolt B, Haxholdt $O$, et al. Immediate and long-term mental recovery from general versus epidural anesthesia in elderly patients. Acta Anaesthesiol Scand 1983; 27: 44-9.

29 Rybanen P, Helkala EL, Ihalainen O, et al. Effects of anaesthesia on the psychological function of patients. Ann Clin Res 1978; 10: 318-22.

30 Diagnostic and Statistical Manual - Text Revision (DSM-IV-TR $\left.^{\mathrm{TM}}, 2000\right)$. First MB (Ed.). STAT! Ref Online Electronic Medical Library. 2000. American Psychiatric Association; 2004: 9-17.

31 Dyer CB, Ashton CM, Teasdale TA. Postoperative delir- ium. A review of 80 primary data-collection studies. Arch Intern Med 1995; 155: 461-5.

32 McCusker J, Cole MG, Dendukuri N, Belzile E. Does delirium increase hospital stay? J Am Geriatr Soc 2003; 51: 1539-46.

33 Inouye SK, Rushing JT, Foreman MD, Palmer RM, Pompei P. Does delirium contribute to poor hospital outcomes? A three-site epidemiologic study. J Gen Intern Med 1998; 13: 234-42.

34 McCusker J, Cole M, Abrahamowicz M, Primean F, Belzile E. Delirium predicts 12-month mortality. Arch Intern Med 2002; 162: 457-63.

35 Moller JT, Cluitmans P, Rasmussen LS, et al. Longterm postoperative cognitive dysfunction in the elderly ISPOCDI study. ISPOCD investigators. International Study of Post-Operative Cognitive Dysfunction. Lancet 1998; 351: 857-61.

36 Newman MF, Grocott HP, Mathew JP, et al.; Neurologic Outcome Research Group and the Cardiothoracic Anesthesia Research Endeavors (CARE) Investigators of the Duke Heart Center. Report of the substudy assessing the impact of neurocognitive function on quality of life 5 years after cardiac surgery. Stroke 2001; 32: 2874-81.

37 Abildstrom H, Rasmussen LS, Rentowl P, et al. Cognitive dysfunction 1-2 years after non-cardiac surgery in the elderly. ISPOCD group. International Study of Post-Operative Cognitive Dysfunction. Acta Anaesthesiol Scand 2000; 44: 1246-51.

38 Marcantonio ER, Goldman L, Orav EJ, Cook EF, Lee $\mathrm{TH}$. The association of intraoperative factors with the development of postoperative delirium. Am J Med 1998; 105: 380-4.

39 Canet J, Raeder J, Rasmussen LS, et al.; ISPOCD2 Investigators. Cognitive dysfunction after minor surgery in the elderly. Acta Anaesthesiol Scand 2003; 47: 1204-10.

40 Trzepacz PT. Is there a final common neural pathway in delirium? Focus on acetylcholine and dopamine. Semin Clin Neuropsychiatry 2000; 5: 132-48.

41 Agostini JV, Leo-Summers LS, Inouye SK. Cognitive and other adverse effects of diphenhydramine use in hospitalized older patients. Arch Intern Med 2001; 161: 2091-7.

42 Grantham C, Geerts $H$. The rationale behind cholinergic drug treatment for dementia related to cerebrovascular disease. J Neurol Sci 2002; 203-4: 131-6.

43 Inouye SK, van Dyck CH, Alessi CA, Balkin S, Siegal AP, Horwitz RI. Clarifying confusion: the confusion assessment method. A new method for detection of delirium. Ann Intern Med 1990; 113: 941-8.

44 Ely EW, Margolin R, Francis J, et al. Evaluation of delirium in critically ill patients: validation of the 
Confusion Assessment Method for the Intensive Care Unit (CAM-ICU). Crit Care Med 2001; 29: 1370-9.

45 Rasmussen LS, Larsen K, Houx P, Skovgaard LT,

Hanning CD, Moller JT; ISPOCD Group; The

International Study of Postoperative Cognitive

Dysfunction. The assessment of postoperative cognitive function. Acta Anaesthesiol Scand 2001; 45: 275-89.

46 Murkin JM, Newman SP, Stump DA, Blumenthal JA. Statement of consensus on assessment of neurobehavioral outcomes after cardiac surgery. Ann Thorac Surg 1995; 59: 1289-95.

47 Murkin JM, Stump DA, Blumenthal JA, McKhann G. Defining dysfunction: group means versus incidence analysis--a statement of consensus. Ann Thorac Surg 1997; 64: 904-5. 